\title{
STS Interactions and the Teaching of Physics and Chemistry
}

\author{
J. SOLBES,* A. VILCHES* \\ Seminar of Investigation and Innovation in Science Education, University of Valencia, Spain
}

Science Education, 81,377-386

\begin{abstract}
The absence of science-technology-society (STS) interactions and its consequences in the basic teaching of science in Spain are analyzed in the first part of this work. This article proposes the introduction of STS interactions in physics and chemistry classes in conjunction with the teaching/learning model of science as research. When such interactions are not introduced, it can be observed that the students have a vision of science that is removed from the world in which they live and are unfamiliar with the mutual relationships between science, technology and the natural, social environments in which they are immersed. Not only do a large number of textbooks fail to cover STS interactions, but the majority of teachers do not consider interactive STS aspects necessary, nor do they contemplate these aspects in instruction. All of this contributes to the lack of students' interest in physics and chemistry and their rejection of them as subjects. In the second part of the work, students of 16-18 years of age in the last 3 years of secondary education were surveyed, and the results obtained were analyzed. These results confirmed that dealing with STS interactions in the classroom established science as something alive, more complete and integrated in the students' environment. Students subsequently developed an improved comprehension and a more real image of these sciences, which allowed them to understand better the role of scientists and how they work. All of this generated positive attitudes toward the study of physics and chemistry and increased the students' interest in their study. Thus the results of this research make it clear that it is possible to transform the learning of physics and chemistry with the inclusion of STS activities, so that the students can build scientific knowledge. Likewise, students integrate essential aspects that affect the scientific activity and contribute to deepening and consolidating their own knowledge.
\end{abstract}

\section{INTRODUCTION}

In recent years, different lines of investigation have been developed, coinciding in analyzing the causes of the decreasing interest of students toward the study of physics and 
chemistry, as well as possible solutions. In the same manner, the changes in society and in science-technology, and also the disconnection between scholastic science and the reality of a scientifically oriented society, have forced a reestablishment of the objectives in the teaching of science. Both paths have converged in a field that has been fruitful and that appears to be an effective strategy in science education, as evidenced by the enormous quantity of literature in regard to this subject (Solomon \& Aikenhead, 1994), and the development of numerous projects and studies related to the treatment of science, technology, and society (STS) interactions in education. The development of the different STS projects attempts to bring the teaching of science closer to the needs of the science student as a member of a society that is more and more technologically developed.

The absence of STS interactions in the teaching of physics and chemistry in Spain and the summing up of results obtained are analyzed in this work. This absence and its consequences are shown through the analysis of normal physics and chemistry textbooks, and the manner in which "teaching" habitually presents these materials (lecture and notetaking/teaching based on those textbooks). Teachers were also surveyed, and the results obtained are also presented to confirm the scant importance given by the teaching staff to STS interactions in the instruction of physics and chemistry. Finally, a proposal for setting up a new model for the teaching/learning of the sciences is made, integrating STS activities to make physics and chemistry courses more interesting and livelier for the students. These materials are presented to experimental groups of students, and the results obtained are compared with the results of those students who never investigated STS interactions in the classroom.

\section{ABSENCE OF STS INTERACTIONS IN SCIENCE TEACHING}

What has been stated in theory through didactic investigation in the last decade as a basic component of the science curriculum for improved comprehension of the nature of science and scientific work is not recognized, in practice, in many countries. First, a large number of textbooks fail to cover such aspects, and teachers are not only neglecting to take this into account in their teaching, but they also have misconceptions about the nature of science and STS interactions (Rubba \& Harkness, 1993).

As we have already demonstrated in an earlier study (Solbes \& Vilches, 1989), through the analysis of 47 science textbooks for 12- and 13-year-olds and physics and chemistry textbooks for 15- and 17-year-olds, the percentage of chapters of these textbooks that included a section, an activity for the student, or a paragraph about the diverse aspects of STS relationships was very low (between $4 \%$ and $17 \%$ ). Thus, it can be confirmed that routine teaching contributes to presenting an image of science and scientists removed from real problems of the world and does not take into account the aspects of STS relationships that mark scientific development.

The theories are presented without any connection to the problems that they try to solve and do not contemplate the role of science in the conception of the world or in the organization of social problems, thus demonstrating an image of neutral science, above ideologies, ignoring serious historic conflicts that form scientific development. In this way, the narrow interactions existing between scientific knowledge and other fields such as philosophy, ethics, religion, or economies are omitted, without taking into account the social influence on scientific and technological development; that is, the influence of socially dominant ideas on the selection of the topics of investigation, the commercial priorities in technological innovation, and the sources 
destined for research and development. And finally the fact, definitively, that science and technology advance in one direction or another influenced by the kind of society in which they are developed and by the institutions that finance them, which implies a clear conditioning of scientific development.

But the work of men and women in science, like any other human activity, does not take place on the margin of the society of the environment in which they live and is logically affected by the historical circumstances of the moment in which it is developed; also, it is influenced at the same time by the social and natural environment in which it is immersed. It is difficult to accept that real learning can take place isolated from the real world. However, the idea that science acts as a phenomenon disconnected from reality (Penick \& Yager, 1986) is very widespread in our society and, as we have made clear, not less so in education.

To test this vision of science as it is taught, we surveyed 212 students in physics and chemistry in their last 3 years of secondary education, chosen at random from the several public centers in the Autonomous Valencian region. The textbooks analyzed, following the usual teaching/learning methodology, were used in the teaching of the students considered our control group. We found, coinciding with other studies (Aikenhead, 1987, 1988; Boyer \& Tiberghien, 1989; Ryan, 1990, Schibeci, 1986), that, in general, students have a vision of science that is removed from the world in which they live. Scientists and the means in which they work appear disconnected from the mutual relationships between science, technology, and the natural and social environments in which they are immersed, and the students ignore the role played by science throughout the history of humanity, as well as the external influence of scientific knowledge, as shown in Table 3 (control group, $N=212$ ).

All of this contributes to the students' lack of interest in physics and chemistry and the rejection of their study, as was shown in the survey through the negative evaluation that the 212 students made of the instruction received in physics and chemistry, including the disinterested and even negative evaluation labels that physics and chemistry deserve from them, as indicated in Table 4 (control group, $N=212$ ). This can be understood if we take into account the aforementioned manner in which education habitually presents this material. However, by recalling the history of science, one realizes the passionate characteristics that have always identified scientific development, which leads once more to the necessity to recover this dimension of science: the historic aspects, STS relationships, adding a potentially motivating factor to its role of showing a more complete and contextualized image.

In fact, the 212 students who were interviewed suggested many aspects and concrete topics related to STS interactions to include in a physics and chemistry course that would interest them. The course should contain concrete applications of both disciplines and the problems that they resolved or raised, the use of new materials and technologies, debates about current scientific topics, the study of coloring and additive chemistry, topics related to the environment, and the problems that technological development has generated (acid rain, problems in the ozone layer . . .) or activities outside the learning center. This lack of interest on the part of the students was also pointed out in a study that we carried out at a later date, from another point of view, in which the students were asked to give their reasons for choosing or not choosing physics and chemistry courses, which are optional in the last 2 years of secondary education. The results (Table 1 ) indicated that, when the students choose these disciplines, the majority do not do so because they are interested in them (i.e. because their study seems appealing or interesting in itself), but rather because the courses are necessary for their further studies. Also, only one fourth of these students declared that they had a theoretical interest in their choice of study. 
TABLE 1

Students' Interest in Physics and/or Chemistry

Percentage

Reason for Choosing Physics/Chemistry:

$(\mathrm{N}=212)$

It is necessary for their professional study

$44.9 \%$

It seems like an interesting subject

$25.2 \%$

A lesser evil: They dislike or are less interested in other options

$19.5 \%$

There was no other option to choose

$10.3 \%$

Not only the absence of treatment of STS relationships in textbooks contributes to the decontextualized vision of science that the students have, but also the minimized importance given by the teaching profession to these aspects in instruction. This was made clear in a study carried out to test the hypothesis according to which we thought that a large proportion of the teaching profession did not adequately value the inclusion of STS interactive aspects in the instruction of physics and chemistry, as was evident in different responses, such as their appraisal of the possible causes of the students' lack of interest in the study of physics and chemistry or in their analyses of current teaching materials.

\section{TEACHERS AND STS RELATIONSHIPS}

One hundred and three secondary physics and chemistry teachers, voluntarily involved in training and improvement courses organized by the different autonomous regions in Spain, were consulted. A high percentage (66.6\%) stated that one of the causes of the students' disinterested and, in some cases, rejection of physics and chemistry is the socially decontextualized image of the sciences habitually presented, which makes their study uninteresting for the student.

This percentage also indicates the disconnection between what they learn and the world in which they live, the apparent uselessness of what they study, the image of science removed from reality without taking into account the social implications, without treating the historical aspects in which they are contextualized, and without explaining the role of scientists in the evolution of society. Another of the most cited causes was related to the teaching methodology by means of a lecture and notetaking (82.5\%) and, to a lesser extent, to the difficulty of the subjects (29.1\%).

However, despite considering that the absence of STS interactions in education is a cause of the lack of interest among students, it is significant that there are many teachers $(89.2 \%)$ who ignore these aspects when analyzing materials used routinely in physics and chemistry classes. Thus, concerning the analysis of the introduction of the concept of energy in a secondary education textbook in which STS aspects are not presented, the results clearly showed the scant consideration the majority of teachers conferred on such aspects: Only $10.8 \%$ noted the absence of these aspects in the material being analyzed and pointed them out as a factor to be taken into account in teaching.

Therefore, it is to be expected that, if the majority of teachers do not consider interactive STS aspects a necessary element, then they evidently do not transmit a complete and contextualized vision of science to their students. Many explain that they do not open up the discipline to daily life because of structural problems relating to their timetable (lack of time), the extension of official contents, etc., and use programs that allow the students to accede to subsequent scientific studies, but without developing those that promote the acquisition of knowledge that would help them comprehend their scientific and technical environment. 
TABLE 2

Teachers' Proposal of Activities

\begin{tabular}{lc}
\hline \multicolumn{1}{c}{ Teachers' STS Proposals: } & $\begin{array}{c}\text { Percentage } \\
(\mathrm{N}=120)\end{array}$ \\
\hline Science/technology relationship & $55.8 \%$ \\
Science/society relationship & $10.8 \%$ \\
Science/environment relationship & $8.3 \%$ \\
Science/history relationship & $0.8 \%$ \\
Activities outside the learning institution & $4.2 \%$ \\
Non-STS activities & $7.5 \%$ \\
Multiple activities & $13.3 \%$ \\
\hline
\end{tabular}

In the same manner, coinciding with other studies (Hodson, 1992) in the elaboration of didactic material and the creation of concrete activities of STS relationships, the lack of interest in a large number of the teachers in some fundamental STS aspects was evident (some even think that they do not need to take these into account in instruction, that it is not their job to exercise these aspects in the discipline, and support the "neutral" character of science as the deposit of impartial knowledge that ignores serious historical conflicts) (Table 2).

In this case, 120 physics and chemistry teachers involved in training and improvement courses in Spain were consulted. Thus, it can be confirmed that these teachers compose a group similar to the one we analyzed previously. Although a large number of the teachers consulted (55.8\%) proposed activities of interaction between science and technology, in general these were simple technical applications of science, confirming the idea that they are less conflictive, constitute the most "neutral" aspects, and are less "removed" from the scientific content.

The multiple activities established contained all the STS relationships, together with other types of activities. The examples described refer to the implications of science on the environment, on society, or on technology, but in no case the other way around; that is to say, there were not any activities about the implications of technological development, society, or environment on scientific progress, for example.

The results are consistent with our hypothesis, which is easily explained if we consider teacher training, in which the STS aspects are not taken into account and, as a result, there is little reason to hope that teachers will have different visions of science and STS relationships than the students (Fleming, 1988).

\section{STS INTERACTIONS IN PHYSICS AND CHEMISTRY CLASSES. PROPOSAL OF A NEW MODEL FOR THE TEACHING/LEARNING OF THE SCIENCES}

After defining the problem, a proposal developed which, in the context of a new model for teaching/learning, could contribute to improving the students' interest in and attitude toward the sciences and their study, helping to afford a vision of science that is more contextualized and more in accordance with the current philosophical and historical positions of science.

With a minimally detailed treatment of STS interactions in teaching, we think that it is possible to improve the students' attitude toward physics and chemistry, increase their interest in the study of science in general, and perfect their learning, providing a more complete and appropriate image of science and how scientists work. 
The proposal is based principally on the establishment of a new model of teaching/learning according to which the experiment of STS relationships was carried out. In this way, the work converges with many projects with a constructivist orientation, such as the treatment of problematic situations of interest bridging the gap between activities introducing concepts, the solution of problems and practical work, responding to the characteristics of a directed investigation (Gil et al., 1991) in which the students' learning is organized as a construction of knowledge following their own conceptions, and involving them in an investigative activity directed by the teacher.

The parallel established between the learning of science and research allows the integration of new didactic advances, among others, those directing attention to other aspects inseparably related to the work of scientists as they are the frame within which this scientific knowledge is developed. This teaching method also emphasizes the relationship between scientists and the outer environment, that is, the influence of society on scientific and technological progress, the problems that their development generates or resolves, the necessity or advisability of development in a particular direction, the influence of scientific knowledge on society and on the exchange of ideas, in other words, the complex STS interactions that mark scientific development.

The inclusion of these aspects in the teaching of the sciences will contribute to:

a. Demonstrating a more socially contextualized image of scientific knowledge;

b. Making a careful study of the problems associated in their construction, which will help understand better the role of science and technology, and that of the scientist;

c. Engaging the students in the solution of serious problems that mortgage the future of humanity: destruction of the natural environment, polarization of rich and poor populations, diseases, nuclear arms, etc;

d. Succeeding in transforming science teaching into a fundamental element of our culture, so as to train critical and responsible citizens (Gagliardi \& Giordan, 1986; Hlebowitsh \& Hudson, 1991), not only in professional efficiency, but also so that they will be able to take an active part in social matters, contributing in this way to making studies meaningful and encouraging interest and positive attitudes.

The conception of the curriculum is proposed in the form of programs of activities by means of which the students can construct and acquire knowledge at the same time as they familiarize themselves with the basic characteristics of scientific work and acquire a critical interest in science and its repercussions. In such programs, the introduction of STS activities is consistent with the established model, pervading all aspects of learning (Vilches, 1993), from the solution of problems, practical work, or the introduction of concepts to their evaluation process; that is to say, not renouncing the construction of coherent bodies of knowledge or presenting the construction of the same as something removed from STS interactions.

This does not imply increasing the curriculum, nor does it mean adding anything new to science studies with a view to forming scientists or future citizens of society; rather it deals with trying to provide a more contextualized idea of science pervading the development of didactic units with activities that take into account the aspects cited. These would converge with the idea that the main objective of teaching science should extend itself beyond the scientific contents and recognize the role of science and technology as a method of solving the problems of humanity with the advantages and disadvantages that their development raises.

Developing as an objective the total comprehension of scientific knowledge, social themes that surround technological development, and increasing the ability to make decisions in a technological society (Fleming, 1989), will remove that ambivalent feeling generated between 
scientific and technological development and its social role that opposes a primarily optimistic vision based on the idea of technology as an instrument of prosperity with a rejection of the products of the technological era and its consequences.

\section{Instruments Developed}

To carry the project through, we first prepared materials for the introduction of STS interactive activities in the physics and chemistry classroom, which were used with 240 secondary school students of 15-17 years of age by different teachers and in different centers during the 1990-1991 and 1991-1992 academic years, using a constructivist methodology of teaching and the previously mentioned programs of activities. These materials were used by the authors on 149 students (experimental group 2) and by three other teachers who were interested in the project on 91 students (experimental group 1).

The project dealt with carefully planned and studied programs in which the activities of STS relationships were presented in each of the aspects of learning, aiming at an internal consistency in the development of the topic, integrated in such a way as to make the students' work meaningful, and contemplating the entirety of the complex interactions, without forgetting the more conflictive aspects.

Students are involved in different activities, from technical applications and the influence of technological development on scientific advancement to the mutual implications of science and technology on society and the environment, from the different social, economic, cultural, and philosophical points of view. All these activities allow students to evaluate and make decisions about different aspects such as economic and social transformations, large-scale military projects, different effects of development, environmental impact, and the contribution of science and technology to the solution of problems.

Considered as useful tools in learning, STS activities were implemented whenever possible. The abstract, decontextualized activities of problem solving or the introduction of concepts were replaced whenever possible by others that put the students in contact with the world around them and with today's problems and their possible solutions, establishing simultaneously activities outside the learning center, the discussion of scientific novelties, lectures by experts, and professionals in the classroom. Some of the STS activities were preceded by an introduction in the form of a discussion about the interest of the problems posed, thereby favoring a more positive attitude toward the work being done; other activities used at the end of a topic included a summary of the work performed and a possible evaluation of the learning process.

By using STS interactions in detail in the science classroom, the student should be able to develop a more complete and contextualized image of physics and chemistry, as well as an increase of interest in their study. In the first part of the survey, a contrast was established by using two questionnaires that the students of the control groups had already answered. The first of these reflects the students' opinions about STS interactions as well as their opinions of physics, chemistry, and scientists. The second deals with the students' interests in physics and chemistry and the study of science (Solbes \& Vilches, 1992; Vilches, 1993).

Results. At the end of the year, the students involved were given the first questionnaire, dealing with their opinion of science, scientists, and STS aspects.

Although just the last 3 years of secondary education were analyzed, the results showed that statistically significant differences were not observed. For this reason, the results are all presented together. Differences do exist in some items: between the groups of our students (experimental group 2) and those of the other teachers (experimental group 1), who followed 
TABLE 3

Students' Views of Physics/Chemistry and STS Relationships

\begin{tabular}{lrrr}
\hline \multicolumn{1}{c}{ Percentage of Students Who Indicated: } & $\begin{array}{c}\text { Control } \\
\mathrm{N}=212\end{array}$ & $\begin{array}{r}\text { Exp. 1 } \\
\mathrm{N}=91\end{array}$ & $\begin{array}{c}\text { Exp. 2 } \\
\mathrm{N}=149\end{array}$ \\
\hline A critically positive image of physics/chemistry & $33.5 \%$ & $68.8 \%$ & $68.8 \%$ \\
An unusual view of scientists & $5.7 \%$ & $33.0 \%$ & $55.0 \%$ \\
Five or more technical applications of physics/chemistry & $13.2 \%$ & $51.6 \%$ & $75.2 \%$ \\
Three or more influences of physics/chemistry on society & $8.0 \%$ & $31.9 \%$ & $59.7 \%$ \\
Three or more influences of society on physics/chemistry & $4.2 \%$ & $15.4 \%$ & $33.6 \%$ \\
Three or more influences of physics/chemistry on the environment & $8.0 \%$ & $20.9 \%$ & $46.3 \%$ \\
Capable of making a critical evaluation & $55.2 \%$ & $83.5 \%$ & $96.0 \%$ \\
\hline
\end{tabular}

the same methodology and materials, but in all cases, significant differences were observed compared to the students that did not take a course involving STS interactions (control group).

The results (Table 3) confirmed that the students achieved an improved image (more real and contextualized) of physics and chemistry. Dealing with STS interactions in the classroom established science as something alive and integrated in the students' environment. In the continuing evolution that helps solve problems that ought to help resolve others generated by development, STS interactions enable the students to understand their role better, which, at the same time, contributes to generating a "critically" positive attitude toward physics/chemistry and their study, as was observed in the debates and their responses.

The students who did not take a course in which STS activities were established throughout the topics were not only incapable of making a critical evaluation in $44.8 \%$ of the cases, but, when they were asked to analyze critically the role played by physics and chemistry in the lives of men and women, weighing the advantages and disadvantages (the latter being much more serious, in the opinion of the majority of the students - destruction of the planet, end of humanity, pollution, nuclear bombs - and irreversible than the former), most of them confused science with the more negative consequences of social and political development such as the arms race or the destruction of the environment. However, we think that the discussion of the social role of science, the myth of the neutrality of the scientist, or the conditioning of scientific progress clearly contribute to the recovery of vitality in the teaching of the sciences.

It was observed in Table 4 that we showed only the results related to the fact that the students who took an STS course showed an improved attitude toward physics/chemistry and their learning, and a greater interest in studying them when they included interactive STS activities. In this case, these experimental students appear in Table 4 as a single group because there are no significant differences among them.

When asked which factors would contribute to increasing their interest in the study of physics/chemistry (item 2), the highest percentage in the experimental groups (79.6\%) and in the control groups (76\%) corresponded to aspects related to the methodology used by the teaching staff. A high percentage of the experimental groups (44.6\%) corresponded to aspects related to STS interactions. It is interesting to note that only $10.4 \%$ of the experimental groups and $9 \%$ of the control groups pointed out the difficulty of the subject as a factor that could contribute to their lack of interest in or negative attitude toward physics/chemistry. High rates (80.2\% control group and 88.3\% experimental group), however, were shown for aspects related to the teacher's method as factors directly related to their negative attitude or lack of interest. 
TABLE 4

Students' Interest in Physics/Chemistry and STS Relationships

\begin{tabular}{lcc}
\hline \multicolumn{1}{c}{ Percentage of Students Who: } & $\begin{array}{c}\text { Control } \\
\mathrm{N}=212\end{array}$ & $\begin{array}{c}\text { Exp. } \\
\mathrm{N}=240\end{array}$ \\
\hline $\begin{array}{l}\text { Positively valued physics/chemistry teaching } \\
\text { Indicated STS interactions as a factor that could increase their interest in } \\
\text { physics/chemistry }\end{array}$ & $26.4 \%$ & $54.2 \%$ \\
Considered interactions interesting during the course & $15.1 \%$ & $44.6 \%$ \\
\hline
\end{tabular}

When asked more specifically which topics could be included in a physics or chemistry course to make it interesting for them (item 3), both groups of students pointed out a significant percentage of aspects related to STS interactions (greater, logically, in the case of the experimental groups that had been in contact with STS interactions throughout the course), current affairs, environmental relationships relevant to their daily lives, applications of the subject, influences on technological development, relationships between science and the natural environment and science, technology and society.

\section{CONCLUSION AND PERSPECTIVES}

The results of the investigation make it clear that it is possible to transform physics and science material with the inclusion of STS activities in the development of each topic, in such a way that the students can build scientific knowledge, integrating essential aspects that affect scientific activity and contribute to deepening their knowledge.

On the other hand, it can be observed that: (1) The students that took a course that dealt with STS activities in the didactic model have a more contextualized, more realistic idea of science, showing significant differences in all cases compared to the students who took a course that did not take these aspects into account; (2) It is possible to improve the students' attitude and to increase their interest in the study of physics and chemistry by dealing with the aspects pointed out by the students.

But to achieve the most satisfactory solution, we will have to take into account that attitudes toward science affect all aspects of learning. It will be necessary to establish concrete proposals from the different aspects of teaching, making sure to generate positive attitudes toward science and its learning, especially if we take into account, as the didactic investigation has demonstrated, that a positive attitude toward science in students leads to greater comprehension and achieves the best overall results in the learning of the subject (Yager \& McCormack, 1989).

The treatment of STS interactions contributes to improving the opinion of science, increasing the students' interest in the subject and the study of physics and chemistry not only because of its motivating character, but also, and above all, because it helps promote a more contextualized image of these disciplines. The inclusion of the study of these aspects in teaching will be important, not only for the forming of citizens of a society that is more and more dependent on science and technology, so that in the future they can adopt a responsible attitude toward scientific and technological development, but also for the forming of future scientists.

Another consequence of the investigation could be the design of STS subjects for students who do not choose science options, with a view to presenting science as one of the fundamental elements of the culture of our time, contributing to the development of one of the most 
fruitful fields of didactic research of the sciences in recent years, which permits a better understanding of the situation of change that teaching and the sciences are undergoing in philosophic and historic fields.

\section{REFERENCES}

Aikenhead, G. S. (1987). High-school graduates' beliefs about Science-Technology-Society. III. Characteristics and limitations of scientific knowledge. Science Education, 71, 459-487.

Aikenhead, G. S. (1988). An analysis of four ways of assessing student beliefs about STS topics. Journal of Research in Science Teaching, 25, 607-629.

Boyer, R., \& Tiberghien, A. (1989). Las finalidades de la enseñanza de la Fsica y la Química vistas por profesores y alumnos franceses. Enseñanza de las Ciencias, 7, 213-222.

Fleming, R. (1988). Undergraduate science students' views on the relationship between science, technology and society. International Journal of Science Education, 10, 449-463.

Fleming, R. (1989). Literacy for a technological age. Science Education, 73, 391-404.

Gagliardi, R., \& Giordan, A. (1986). La historia de las ciencias: Una herramienta para la enseñanza. Enseñanza de las ciencias, 4, 253-259.

Gil, D., Carrascosa, J., Furió, C., \& Martínez, J. (1991). La Enseñanza de las Ciencias en la Educación Secundaria. Barcelona: Horsori.

Hlebowitsh, P. S., \& Hudson, S. E. (1991). Science education and the reawakening of the general education ideal. Science Education, 75, 563-576.

Hodson, D. (1992). In search of a meaningful relationship: An exploration of some issues relating to integration in science and science education. International Journal of Science Education, 14, 541-562.

Penick, J. E., \& Yager, R. E. (1986). Trends in science education: Some observations of exemplary programme in the United States. European Journal of Science Education, 8, 1-8.

Rubba, P. A., \& Harkness, W. L. (1993). Examination of preservice and in-service secondary science teachers' beliefs about science-technology-society interactions. Science Education, 77, 407-431.

Ryan, A. G. (1990). Los efectos de la región, número de asignaturas de ciencias cursadas y sexo sobre la opinión de los estudiantes canadienses en cuestiones de ciencia, técnica y sociedad. Enseñanza de las Ciencias, 8, 3-10.

Schibeci, R. A. (1986). Images of science, scientists and science education. Science Education, 70, 139-149.

Solbes, J., \& Vilches, A. (1989). Interacciones ciencia, técnica, sociedad. Un instrumento de cambio actitudinal. Enseñanza de las Ciencias, 7, 14-20.

Solbes, J., \& Vilches, A. (1992). El modelo constructivista y las relaciones ciencia, técnica, sociedad. Enseñanza de las Ciencias, 10, 181-186.

Solomon, J., \& Aikenhead, G. (Eds.) (1994). STS education: international perspectives on reform. New York: Teachers College Press.

Vilches, A. (1993). Las Interacciones CTS y la Enseñanza de las Ciencias Físico-químicas. Tesis doctoral, Universidad de Valencia.

Yager, R. E., \& McCormack, A. J. (1989). Assessing teaching/learning in multiple domains of science and science education. Science Education, 73, 45-58. 